\title{
La influencia de la geopolítica estadounidense en la Teología de la Liberación latinoamericana en el periodo 1960-1990
}

\author{
Juan Pablo SOMIEDO GARCíA \\ Área de Estudios Estratégicos e Inteligencia \\ Universidad Autónoma de Madrid \\ jupasom@yahoo.es
}

Recibido: 07-03-2014

Aceptado: 15-06-2014

\section{RESUMEN}

El artículo repasa los motivos que llevaron a los EE UU a interpretar el nuevo movimiento eclesial de la Teología de la Liberación en América Latina como una amenaza a sus intereses en el continente y a combatirlo en los ámbitos político y cultural. Entender correctamente las causas y derivaciones de la postura de los EE UU frente al naciente movimiento eclesial exige situarlo dentro del marco más amplio de actores y variables en el que se desenvolvió la Guerra Fría y en el que Latinoamérica era un escenario más de la confrontación. Por su parte, la Iglesia Católica escenificaría, una vez más, la falta de alineación entre su vertiente política y su vertiente pastoral y evangélica.

Palabras clave: geopolítica de la religión; relaciones internacionales; teología de la liberación; Vaticano; América Latina.

\section{The Influence of US' Geopolitics in the Latin American Liberation Theology in the Period 1960-1990}

\begin{abstract}
The article reviews the reasons that led the USA to interpret the new ecclesial movement of Liberation Theology in Latin America as a threat to their interests in the continent and fight it in the political and cultural areas. Correctly understand the causes and derivations of the US stance against implies putting emerging church movement within the broader actors and variables in which the Cold War unfolded and in which Latin America was a more confrontational scenario frame. For its part, the Catholic Church represents, again, the lack of alignment between its politics and its pastoral and evangelical side.
\end{abstract}

Key words: geopolitics of religion; international relations; liberation theology; Vatican; Latin America. 


\title{
A influência da geopolítica estadunidense na Teologia da Libertação latino-americana no período 1960-1990
}

\begin{abstract}
RESUMO
O artigo repassa os motivos que levaram aos EE UU a interpretar o novo movimento eclesial da Teologia da Libertação em América Latina como uma ameaça a seus interesses no continente e a combater nos âmbitos político e cultural. Entender corretamente as causas e derivações da postura dos EE UU em frente ao nascente movimento eclesial exige situá-lo dentro do marco mais amplo de atores e variáveis no que se desenvolveu a Guerra Fria e no que Latino América era um palco mais da confrontação. Por sua vez, a Igreja Católica encenaria, uma vez mais, a falta de alinhamento entre sua vertente política e sua vertente pastoral e evangélica.
\end{abstract}

Palavras-chave: geopolítica da religião; relações internacionais; teologia da libertação; Vaticano; América Latina.

\section{REFERENCIA NORMALIZADA}

Somiedo, Juan Pablo (2014) "La influencia de la geopolítica estadounidense en la Teología de la Liberación latinoamericana en el periodo 1960-1990”. Geopolítica(s). Revista de estudios sobre espacio y poder, vol. 4, núm. 2, 79-98.

SUMARIO: Introducción. 1. Los orígenes de la Teología de la Liberación y su desarrollo posterior. 2. Claves del posicionamiento de la política exterior de EE UU en torno a la cuestión de la Teología de la Liberación. 3. La Guerra Fría cultural como elemento catalizador. 4. El nuevo Papa y la Teología de la Liberación. Bibliografía.

"Ya sois la verdad en cruz y la ciencia en profecía y es total la Compañía, compañeros de Jesús.

El juramento cumplido, la UCA y el pueblo herido dictan la misma lección desde las cátedras fosas y Obdulio cuida las rosas de nuestra liberación". Extracto del poema que Pedro Casaldáliga dedicó a los jesuitas de la UCA

\section{Introducción}

El fin de la Segunda Guerra Mundial marca el surgimiento de Estados Unidos de América y la Unión Soviética como potencias rivales y un mundo bipolar que es testigo del enfrentamiento simétrico entre las dos potencias. Este enfrentamiento, conocido como la Guerra Fría (Cold War), comenzó en 1946 y terminaría en 1991 con la disolución de la URSS y del bloque económico y militar soviético (Leffler, 2008).

La política exterior estadounidense en materia de seguridad nacional se ha instrumentado a través de doctrinas o estrategias de seguridad. Una doctrina de seguri- 
dad nacional es un conjunto de enunciados que expresa las visiones generales que los líderes políticos tienen acerca de cuáles son las oportunidades y amenazas que enfrenta el país y propone un conjunto desagregado de estrategias para hacer frente a ese escenario. Simplificando podemos afirmar que las doctrinas de seguridad nos brindan una "imagen del mundo" y una "hoja de ruta" para conducirse en él.

Dos de estas doctrinas configuraron la política exterior norteamericana en el área de Latinoamérica durante la Guerra Fría. Una de ellas, la doctrina Monroe, atribuida a James Monroe, quinto presidente de los EE UU, fue invocada por varios presidentes, entre ellos Kennedy y Reagan. El objetivo básico de la doctrina se resumía en la conocida frase "América para los americanos" y no era otro que impedir las injerencias de los Estados europeos en el continente americano, pero en la práctica sirvió de base para realizar precisamente lo que se trataba de impedir a otras potencias. Según Noam Chomsky esta doctrina ha funcionado como una declaración de la hegemonía y el derecho a la intervención unilateral de los Estados Unidos de América en Latinoamérica. Por poner sólo un ejemplo, Roosevelt la invocó para apoyar la intervención en la colonia española de Cuba en 1898. En 1980, James G. Blaine formuló lo que se considera una extensión de la doctrina Monroe, la doctrina Big Sister tenía como objetivo reunir a las naciones de América Latina bajo el paraguas del liderazgo imperialista de EE UU y abrir sus mercados a los intereses de ese país. Pero mucho antes, en 1954, el Secretario de Estado John Foster Dulles, hermano de Allan Dulles, director de la Central Intelligence Agency (CIA) y a la vez miembro del consejo ejecutivo de la United Fruit Company, invocó esta doctrina en la Décima Conferencia Panamericana denunciando la intervención del comunismo soviético en Guatemala. Este hecho desembocó en la planificación y ejecución por parte de la CIA de la "Operación PBSUCCESS"1. Pero seguramente debemos encontrar la motivación profunda de esta operación en que el presidente Jacobo Arbenz pretendía nacionalizar terrenos de la United Fruit Company para repartir esas hectáreas entre los campesinos. Allan Dulles no tardaría en expresar su inquietud a su hermano, a la sazón, Secretario de Estado.

La otra doctrina que jugó un papel preponderante fue la bautizada como "estrategia de contención" de George Kennan que intentó frenar el avance soviético, en particular el control sobre Eurasia, y su proyección del comunismo como tipo de régimen. Para esto se basó en un conjunto de políticas como la creación de la OTAN y el apoyo a la integración europea, en una estrategia de disuasión y en unos recursos como el Plan Marshall. La esencia de sus postulados, aunque con ajustes, se mantuvo durante toda la Guerra Fría.

\footnotetext{
${ }^{1}$ El 17 de junio de 1954 fuerzas mercenarias y un puñado de militares guatemaltecos, encabezados por Castillo Armas, invadieron Guatemala desde la vecina Honduras, para derrocar al gobierno constitucional de Jacobo Arbenz. La invasión planificada, financiada y dirigida por la CIA, contó también con el respaldo del presidente de Honduras, Manuel Gálvez, y del dictador de Nicaragua, Anastasio Somoza.
} 
La doctrina de Kennan se apoyó también en la archiconocida teoría del dominó, atribuida a John Foster Dulles, que planteaba la posibilidad de que en una determinada región, la caída de uno de los Estados clave en manos del comunismo podría conducir a un efecto parecido al de las fichas de dominó cuando caen y arrastran a las otras en su caída.

Mientras tanto, la Iglesia se estaba transformando debido a la "primavera eclesial" que había supuesto el aggiornamiento a raíz del Concilio Ecuménico Vaticano II, convocado por el Papa Juan XXIII. Después del corto periodo del papado de Juan Pablo I, fue Juan Pablo II quien ocupó la sede petrina. El Papa venido del frío pronto comenzó a luchar contra el comunismo que tan de cerca había vivido en su país natal de Polonia. Tampoco él era un desconocido para el comunismo. El politólogo polaco Andrzej Rajewski describe con todo lujo de detalles cómo Juan Pablo II había sido seguido de cerca tanto por los servicios de inteligencia de la URSS, el temido Komitet Gosudárstvennoj Bezopásnosti (KGB), como por los de Polonia, el Sluzba Bezpieczenstwa (SB). En su juventud, como estudiante universitario, Wojtyla aparece mencionado en los informes como integrante de la resistencia cultural frente al nacional-socialismo y al comunismo; posteriormente, es fichado por las fuerzas de seguridad como seminarista clandestino, sacerdote y párroco; más tarde como cardenal, es señalado como de "alto riesgo"; finalmente, al ser elegido Papa en octubre de 1978, pasa a ser una "prioridad absoluta" para los servicios de inteligencia de Moscú, que organizaría la operación ${ }^{2}$ que acabaría con el atentado al Papa en mayo de 1981 en la Plaza de San Pedro (Rajewski, 2008: 177-197).

Otra página interesante y poco estudiada fue la colaboración de unos cuantos sacerdotes que hicieron la labor de espías para la policía secreta comunista, ya desde sus tiempos como obispo auxiliar de Cracovia. Algunos de ellos han fallecido en fechas relativamente recientes; tal es el caso del padre Sadus, quien ocupaba la parroquia de Cracovia, y que murió en 1990; o el del padre Szczotkowski, quien ocupaba el cargo de canónigo en la catedral de Cracovia y murió en 2000 (Somiedo, 2013: 2-3).

Tanto Juan Pablo II como Ronald Reagan representan simultáneamente la conducción y los resultados de un avance conservador que se gestó como reacción a experiencias de renovación previas tanto en la Iglesia Católica como en EE UU. Finalmente, el tridente que formó junto con Margaret Thatcher y Ronald Reagan pronto acabaría por derrumbar el Muro de Berlín, o, en palabras de Churchill, el telón de acero que había caído desde Stetin a Trieste (Ezcurra, 1986: 100-105).

\footnotetext{
${ }^{2}$ Para llevar a cabo la operación, el KGB solicitó la colaboración de la DS (servicios de inteligencia búlgaros), que se puso en contacto con un turco de 23 años llamado Alí Agca. Agca pertenecía al Partido de Acción Nacional - también conocido como los Lobos Grises-, un grupo nacionalista islámico manipulado por el KGB. Además, había recibido entrenamiento como terrorista en Siria y, en 1979, había participado en el asesinato de un editor turco de carácter liberal.
} 
Algunos países de Latinoamérica como Perú, Guatemala, Colombia o Nicaragua seguían siendo para el Vaticano "tierra de misión". En particular España, debido a la vinculación histórica, aportó muchos de esos misioneros y misioneras cuyo objetivo era anunciar el Evangelio acompañándolo de la promoción humana en unas regiones frecuentemente devastadas por la pobreza y la injusticia.

Los cambios adoptados por la Iglesia a partir del Concilio Vaticano II fueron aprovechados por los teólogos más heterodoxos, tanto en Europa, donde se habían formado académica e intelectualmente los teólogos latinoamericanos, como en la propia Latinoamérica para tratar de dar una respuesta desde la fe a la situación social y económica de unas masas oprimidas y explotadas. Los ideólogos más importantes de la Teología de la Liberación fueron el peruano Gustavo Gutiérrez Merino, quien en 1973 publica la obra Historia, política y salvación de una Teología de la Liberación, el brasileño Leonardo Boff, y los jesuitas españoles Ignacio Ellacuría y Jon Sobrino. Como afirmó el propio Gustavo Gutiérrez, la Teología de la Liberación se formuló la pregunta: ¿hay una relación entre construir el mundo y salvarlo?

Cuando aparecieron los primeros bosquejos de la Teología de la Liberación, a finales de los años 1960 y principios de los 1970, parecían posibles varios caminos para un cambio estructural básico en la sociedad. Operaban movimientos de guerrilla en varios países de Latinoamérica, aunque el fracaso y la muerte del Che Gueva$\mathrm{ra}^{3}$ en Bolivia en 1967 parecía ser un presagio de lo que iba a suceder.

Al mismo tiempo, los Estados Unidos se sumergieron de lleno en una guerra fría cultural encubierta con el objetivo de contrarrestar la creciente influencia de las corrientes marxistas y comunistas en la vieja Europa pero también en todo Latinoamérica.

\section{Los orígenes de la Teología de la Liberación y su desarrollo posterior}

La Teología de la Liberación no nace ni en EE UU ni en Europa, sino en América Latina, en un contexto histórico determinado y determinante. Este origen no es casual, pues una reflexión sobre la fe a partir de las inquietudes de los sectores más

\footnotetext{
${ }^{3}$ El mito construido sobre el Che Guevara dista mucho de ser real, como bien apunta el historiador Enrique Ros (2002). Como guerrillero y estratega era pésimo como han dejado claro sus propios compañeros de guerrilla, entre ellos el capitán Dariel Alarcón. Como ideólogo también fracasó, pues ningún intelectual marxista formado lo tomó como referencia intelectual. Entre otras cosas cuenta en su diario cómo fusiló él mismo a varios compañeros de guerrilla. Entre sus víctimas también figuraron campesinos inocentes. En 1964, ante la asamblea de Naciones Unidas sentenció: "Hemos fusilado, fusilamos y seguiremos fusilando mientras sea necesario". Finalmente él mismo fue fusilado en La Higuera por el sargento Mario Terán cumpliendo órdenes del oficial Félix Rodríguez.
} 
populares que sufren la injusticia difícilmente podría haber nacido en los países ricos.

La Teología de la Liberación no es una corriente homogénea y ha manifestado diferentes aproximaciones dependiendo de la situación y las circunstancias concretas del país donde tomó forma. Así podemos encontrar desde sacerdotes que toman las armas y se unen a la guerrilla como Camilo Torres en el Ejército de Liberación Nacional (ELN) hasta posturas menos activas pero teóricamente igualmente comprometidas como las del peruano Gustavo Gutiérrez o el español Ignacio Ellacuría. Sintéticamente podemos diferenciar cuatro etapas en el desarrollo de la Teología de la Liberación:

\section{Primer Periodo: 1959-1967}

La Teología de la Liberación hunde sus raíces en el Concilio Vaticano II, iniciado por el Papa Juan XXIII y clausurado por Pablo VI (1962-1966), en el que grandes teólogos como Congar, Henri de Lubac o Karl Rahner centraron sus discusiones es aspectos sociales y políticos tratando de renovar la Iglesia a la luz de "los signos de los tiempos". A partir de ahí la Iglesia adopta un cambio de mentalidad y una serie de transformaciones que son aprovechados por los teólogos más heterodoxos.

En esta primera etapa la Teología de la Liberación se va gestando, buscando definirse a sí misma y toma contacto con las corrientes filosóficas que se han dado en llamar "filosofía de la liberación latinoamericana", impregnadas de influencias althusserianas y tomistas entre otras y de fuerte raigambre marxista (Rabadán, 2012: 2).

Políticamente el hecho más relevante en América Latina en estos años fue la Revolución cubana con el triunfo de Fidel Castro en 1959 que abrió el paso al socialismo en Latinoamérica. Por primera vez el mundo tomó conciencia de que la situación de pobreza y miseria en América Latina podía ser explosiva. Así, en 1961 el gobierno de Kennedy lanza su Alianza para el Progreso, para ayudar al desarrollo de los pueblos de Latinoamérica.

El golpe de Estado de 1964 en Brasil da el pistoletazo de salida a un tipo de gobiernos militares que se extenderá por todo el cono sur en años sucesivos. La muerte del Che en 1967 será el inicio de los focos de guerrillas por todo el continente.

\section{Segundo Periodo: 1968-1971}

Políticamente estos años están marcados por evoluciones y cambios importantes. La Revolución peruana de Velasco Alvarado en 1968, la subida al poder en Chile del socialista Allende en 1970, el gobierno popular de J. J. Torres en Bolivia en 1970, el regreso de Perón a Argentina en 1972 aparecían como signos de esperanza. Sin embargo, nada más lejos de la realidad. En 1969 el informe Rockefeller afirmaba que la única institución seria, digna de ser tenida en cuenta, en Latinoamérica es 
la militar. Desde entonces en Panamá comenzó a funcionar una Escuela Militar que formará durante 25 años a las plantillas de los futuros gobiernos militares de toda América Latina.

Desde la perspectiva económica, los economistas brasileños Theotonio dos Santos, Celso Furtado y Cándido Mendes, desarrollan y comienzan a difundir en América Latina la teoría de la dependencia, según la cual, la miseria del continente no sería causada simplemente por el subdesarrollo, sino que sería consecuencia directa de los imperios coloniales y neocoloniales. La conclusión final era que no se podía salir del subdesarrollo permaneciendo dentro de la lógica del capitalismo imperialista.

A nivel eclesial el acontecimiento más importante fue la reunión del Episcopado Latinoamericano en Medellín en 1968 para aplicar el Concilio Ecuménico Vaticano II a América Latina. Pero no fue una simple aplicación sino una relectura del Concilio desde América Latina. Las tres opciones fundamentales que se adoptaron en Medellín fueron: opción por los pobres, opción por la liberación integral de la persona (no solo espiritual, sino también social) y la opción por las comunidades de base como germen de la Iglesia.

Tercer Periodo: 1972-1976

En todo el Cono Sur se suceden los gobiernos militares: Chile (Pinochet, 1973), Argentina (Videla, 1976), Bolivia (Bánzer, 1971), Uruguay (1973). Además conocen gobiernos militares Brasil, Perú, Paraguay, Nicaragua. Guatemala, El Salvador y Panamá.

Para los hombres de Iglesia comprometidos con la causa de los pobres comienza un periodo oscuro de sangre y martirio. La Teología de la Liberación profundiza sobre el tema del cautiverio y el exilio del pueblo de Israel y entra en contacto con los sectores oprimidos de América del Norte (negros y chicanos) y con otras teologías del Tercer Mundo (África y Asia).

\section{Cuarto Periodo: 1977-1989}

La elección de Juan Pablo II al trono pontificio en 1978 y la ascensión de Reagan a la presidencia de EE UU en 1980 marcan un punto de inflexión para la Teología de la Liberación, pues ambos, junto con Margaret Thatcher forman un tridente contra el enemigo común del comunismo y éste y la Teología de la Liberación son fatalmente identificados como sinónimos. El informe del Comité de Santa Fe de 1980, documento secreto y programático del gobierno de Reagan para Latinoamérica, es claramente contrario a las comunidades de base eclesiales y a la Teología de la Liberación, que considera contraria a los intereses de los EE UU en el continente. 
A pesar de todo, la Iglesia de Latinoamérica se mantiene firme y la III Conferencia del Episcopado Latinoamericano en Puebla (México) en 1979 se convierte en una confirmación serena de los postulados de Medellín. Pero las críticas y dificultades contra la Teología de la Liberación aumentan desde dentro de la institución y en 1984, como veremos más adelante en este mismo trabajo, una Instrucción de la Sagrada Congregación para la Doctrina de la Fe del cardenal y futuro Papa Joseph Ratzinger, advierte de los posibles riesgos y desviaciones de dicha teología.

La Teología de la Liberación convierte el anuncio del Evangelio en un doble movimiento de anuncio de la Buena Noticia y denuncia de las injusticias sociales y económicas, pasando a ser, en palabras de Helder Camara, "la voz de los que no tienen voz".

Finalmente, 1989 será el año de la caída del Muro de Berlín, pero también del asesinato de los jesuitas de El Salvador ${ }^{4}$, que marca el alejamiento definitivo del Vaticano de los presupuestos de la Teología de la Liberación.

\section{Claves del posicionamiento de la política exterior de EE UU en torno a la cuestión de la Teología de la Liberación}

Parece una especie de ironía histórica que fuera el presidente Ronald Reagan (protestante) y no el católico John F. Kennedy, y el Papa Juan Pablo II, quienes el 10 de Enero de 1984 acordaran que Estados Unidos tuviera representación en Roma a través de un embajador (Gillis, 2013: 52).

Ronald Reagan llegó a la presidencia resuelto a mejorar las relaciones de los EE UU con Latinoamérica y a restaurar la predominancia norteamericana en el hemisferio occidental después de la administración de Jimmy Carter, al que se señalaba como el responsable de minar la influencia de los Estados Unidos de América en el hemisferio, desestabilizando gobiernos amigos como el de Somoza en Nicaragua y facilitando la influencia cubana y soviética. Esto concentró la mayoría de sus preocupaciones en temas de política exterior durante el primer año de su mandato. Pero la administración Reagan se topó con problemas y escollos derivados, en gran parte,

\footnotetext{
${ }^{4}$ Los jesuitas fueron asesinados por un comando del Batallón Atlacatl entrenado en la Escuela de las Américas. La historia no deja de tener sus curiosidades porque uno de los jesuitas asesinados fue Ignacio Martín Baró. Un sobrino suyo, Carlos Baró Ollero, agente del CNI, moriría en Irak en 2003 junto con seis de sus compañeros [Ver URL: <http://elpais.com/elpais/2003/12/01/actualidad/1070270225_850215.html>, consultado el 18 de Octubre de 2013]. No menos curioso es comprobar como la antena del CESID en el Salvador se desmanteló ocho meses antes del asesinato de los jesuitas [Ver URL: $<$ http://www.canarias7.es/articulo.cfm?id=148194\&p=2>, consultado el 10 de Marzo de 2014]. Una síntesis de mi opinión al respecto puede consultarse en una entrevista que han realizado al autor de este artículo; ver URL: <http://www.youtube.com/watch?v=KOzuBMwvHsY>, consultado el 14 de Enero de 2014.
} 
de sus propias políticas y para finales de 1982 las relaciones con Latinoamérica eran tan problemáticas como siempre (Lowenthal, 1983: 26).

Pero el recorrido de la Teología de la Liberación había comenzado mucho antes. A finales de la década de los 1960. El Concilio Vaticano II y Medellín habían sido claros en su apuesta por la opción comprometida de los pobres y su causa. Los sectores conservadores americanos pronto comprendieron lo que esto podía significar en Latinoamérica.

Por paradójico que parezca, la primera crítica a la Teología de la Liberación no procedió del Vaticano, sino del Informe Rockefeller en 1969, un año después de la gira del vicepresidente de Nixon por Latinoamérica. En él se afirmaba que la Iglesia ya no era un aliado seguro para los EE UU y la garantía de la estabilidad social en el continente y que ésta se había convertido en un centro peligroso de revolución potencial. También se aconsejaba contrarrestar la influencia de la Iglesia católica con la de otro tipo de iglesias o sectas protestantes ${ }^{5}$ más afines con los intereses de los EE UU en el continente.

Una década después, en mayo de 1980, se confeccionarían los documentos secretos de Santa Fe, los cuales se convertirían de facto en la base de la doctrina ético-religiosa de la administración Reagan para el continente latinoamericano (Selser, 1988). Este documento llevaba el sugerente título: "Una nueva política interamericana para la década de 1980". Fue escrito por cinco autores, tres de los cuales (Roger Fontaine, el general Gordon Sumner y Lewis Tambs) entraron a formar parte de la Administración Reagan. En él se planteaba volver a la doctrina Monroe. Se advertía que la Tercera Guerra Mundial ya había comenzado, que Latinoamérica era los "ijares vulnerables" de los Estados Unidos y que la región entera corría el riesgo de caer ante los avances soviético-cubanos. El documento llegaba a aconsejar incluso una "guerra de liberación nacional" contra Fidel Castro (Lowenthal, 1983: 27).

Con relación al tema religioso aconsejaba "combatir por todos los medios a la Teología de la Liberación y controlar los medios de comunicación de masas para contrarrestar la mala imagen de los EE UU en la región". De igual forma se afirmaba que los teólogos de la liberación usaban esta teología como arma política contra la propiedad privada y el capitalismo productivo.

Así las cosas, se crea en abril de 1981 el Instituto de Democracia y Religión para integrar a todas las iglesias evangélicas y financiar su predicación en el continente. De igual forma, se apoya económicamente a los arzobispos más conservadores como el caso de Miguel Obando y Bravo, arzobispo de Managua.

\footnotetext{
${ }^{5}$ Entre los "planes de conquista" evangélicos financiados y apoyados por los EE UU caben destacar el "Plan Amanecer" y el "Ad 2000".
} 
Poco tiempo después, el 7 de Junio de 1982, Reagan se reunía con Juan Pablo II en el Vaticano. Al mismo tiempo, el cardenal Agostino Casaroli y el arzobispo Achille Silvestrini hacían lo propio con el secretario de Estado Alexander Haig y el juez William Clark, consejero de Seguridad Nacional de Reagan. Juan Pablo II estaba convencido que para preservar la influencia de la Iglesia Católica en Latinoamérica, socavada por Washington, sólo cabía la opción de buscar un compromiso con la Casa Blanca. Desde esta fecha, el Vaticano actuó de acuerdo con los Estados Unidos privilegiando el fortalecimiento de la Iglesia (Kourliandsky, 2013: 61). Como sucediera en épocas históricas anteriores esto terminaría por revelar la divergencia entre la Iglesia entendida en su vertiente pastoral y evangélica y la Iglesia en su vertiente política. La falta de alineación de ambas vertientes y las tensiones generadas terminarían por hacer romper la cuerda por el sitio más débil.

Un año después, en 1983, a su llegada al aeropuerto de Managua, en una imagen que ha quedado para la historia, el Papa Juan Pablo II, recientemente canonizado como santo, escenificó la que iba a ser su línea rectora para Latinoamérica. Después de descender por las escaleras del avión recriminó públicamente la conducta del sacerdote Ernesto Cardenal, ministro del gobierno de Nicaragua. Sus acciones no se quedaron ahí. En 1987 legitimó al dictador Augusto Pinochet y unos años más tarde hizo lo mismo en Cuba con Fidel Castro. El objetivo era siempre el mismo, esto es, crear una relación de fuerza políticamente favorable a los intereses de la Iglesia. Tuvo sus frutos. La iglesia chilena consiguió espacio para seguir trabajando a favor de los perseguidos mediante la Vicaría de la Solidaridad y en Cuba volvió a tener la posibilidad de abrir un seminario.

En la línea de Juan Pablo II, la Santa Sede actuó configurando una tenaza alrededor de los ideólogos y curas y de la Teología de la Liberación. El propio Juan Pablo II pidió a la Congregación para la Doctrina de la Fe, presidida por el entonces cardenal Ratzinger y futuro papa Benedicto XVI, un extenso estudio sobre este movimiento que se tradujo en dos textos: la Instrucción Libertatis Nuntius (Instrucciones sobre algunos aspectos de la Teología de la Liberación) en 1984 y la Libertatis Conscientia (Instrucción sobre Libertad Cristiana y Liberación) en 1986, que, aunque dirigidos en un primer momento a sistematizar este movimiento dentro de la Iglesia, expresan las serias reservas de la Santa Sede hacia la Teología de la Liberación.

La Libertatis Nuntius advertía que el análisis de la realidad social que hacía la Teología de la Liberación utilizaba herramientas marxistas. Sin embargo, no toda la Teología de la Liberación estaba en la mira de la Congregación, así como tampoco su "opción preferencial por los pobres". Sólo se condenaba el análisis marxista que algunos teólogos estaban utilizando. Así se puede leer:

Pero el término científico ejerce una fascinación casi mítica, y todo lo que lleva la etiqueta de científico no es de por sí realmente científico. Por esto precisamente la utilización de un método de aproximación a la realidad debe estar precedido de un 
examen crítico de naturaleza epistemológica. Este previo examen crítico le falta a más de una teología de la liberación (Instrucción Libertatis Nuntius, 1984: 4).

De este modo, los teólogos caían en el error de que "creyendo aceptar solamente lo que se presenta como un análisis, resulta obligado aceptar al mismo tiempo la ideología" (Instrucción Libertatis Nuntius, 1984: 6). Se critica también la ideología marxista en su "necesidad objetiva de entrar en la lucha de clases. La verdad es verdad de clase, no hay verdad sino en el combate de la clase revolucionaria" (Instrucción Libertatis Nuntius, 1984: 5).

Visto todo lo anterior parece que estamos ante un documento pretendidamente aclaratorio más que condenatorio. Más que hablar de los errores de la Teología de la Liberación en su conjunto habría que hablar de los errores de un determinado tipo de Teología de la Liberación.

La Instrucción Libertatis Conscientia, en línea con lo que expresaría el Papa un año después en la Encíclica Sollicitudo rei sociales, insiste en que la libertad se ha de fundamentar en el desarrollo de los pueblos no sólo en lo económico. Se propone entonces una liberación que abarque la dimensión cultural, trascendente y religiosa del hombre y la sociedad.

De igual forma se distingue entre evangelización y promoción de la justicia priorizando la primera de ellas: "La Iglesia no se aparta de su misión cuando se pronuncia sobre la promoción de la justicia en las sociedades humanas o cuando compromete a los fieles laicos a trabajar en ellas, según su vocación propia. Sin embargo, procura que esta misión no sea absorbida por las preocupaciones que conciernen el orden temporal, o que se reduzca a ellas" (Instrucción Libertatis Conscientia, 1986: 64). Esto contrastaba con la opinión y la acción cotidiana de muchos de los misioneros y misioneras para los que un concepto estaba estrechamente ligado al otro. Y también contrasta con lo que más abajo se afirma en el mismo documento:

No obstante, la prioridad reconocida a la libertad y a la conversión del corazón en modo alguno elimina la necesidad de un cambio de las estructuras injustas. Es, por tanto, plenamente legítimo que quienes sufren la opresión por parte de los detentores de la riqueza o del poder político actúen, con medios moralmente lícitos, para conseguir estructuras e instituciones en las que sean verdaderamente respetados sus derechos (Instrucción Libertatis Conscientia, 1986: 75).

Pero en ese mismo punto vuelve a dar un giro interpretativo, y así se puede leer:

En consecuencia, no se puede aceptar pasivamente, y menos aún apoyar activamente, a grupos que, por la fuerza o la manipulación de la opinión, se adueñan del aparato del Estado e imponen abusivamente a la colectividad una ideología importada, opuesta a los verdaderos valores culturales del pueblo. A este respecto, conviene recordar la grave responsabilidad moral y política de los intelectuales (Instrucción Libertatis Conscientia, 1986: 75). 
El texto parece obviar aquí que en muchos países de Latinoamérica la primera violencia era la que se ejercía desde el mismo Estado, obteniendo después una respuesta desde el pueblo oprimido. Es decir, bajo el pretexto de estar siendo manipulados ideológicamente, hace caer la carga de responsabilidad en el pueblo de una manera generalizada y sin prestar atención a las particularidades y condicionantes de cada país y gobernante.

Se bascula hacia el concepto de solidaridad en detrimento de la justicia social. Así podemos leer: "Los graves problemas socio-económicos que hoy se plantean, no pueden ser resueltos si no se crean nuevos frentes de solidaridad: solidaridad de los pobres entre ellos, solidaridad con los pobres, a la que los ricos son llamados, y solidaridad de los trabajadores entre sí" (Instrucción Libertatis Conscientia, 1986: 89). De esta forma se anestesia la voluntad de lucha por la transformación social desde un punto de vista cristiano y se la deslegitima moralmente.

Si bien no llegó a enterrarla definitivamente, Juan Pablo II sí logró frenar el avance y la expansión de la Teología de la Liberación, que él interpretó como alineada con el comunismo. Mientras tanto, los hombres de Iglesia que la defendían fueron marginados y olvidados a su suerte. En el periodo entre los años 1964 y 1985 más de cien religiosos y religiosas fueron asesinados. Y el derramamiento de sangre no había terminado, como tristemente demostraron los asesinatos de los jesuitas en la UCA de El Salvador. La firma del acuerdo entre el gobierno y el FMLN, llevada a cabo en 1992, supuso para El Salvador el inicio de ese proceso de paz con el que habían soñado tanto Monseñor Romero como los jesuitas de la UCA.

Mucho tiempo después de estos acontecimientos, el 14 de Marzo en 2007, la Sagrada Congregación para la Doctrina de la Fe, publicó una Notificación sobre las obras de Jon Sobrino ${ }^{6}$ Jesucristo liberador (1991) y La fe en Jesucristo. Ensayo sobre las víctimas (1999). La Congregación justificaba su actuación dada "la amplia divulgación de estos escritos y el uso de los mismos en seminarios y otros centros de estudio, sobre todo en América Latina". En Julio de 2004 se había enviado al autor, a través del general de la Compañía de Jesús Peter Hans Kolvenbach, un elenco de proposiciones erróneas o peligrosas encontradas en los libros citados. En marzo de 2005, Sobrino envió su respuesta a la Congregación sin que esta resultara satisfactoria. Como resultado en 2007 se notificó oficialmente que las obras del autor presentaban "notables discrepancias con la fe de la Iglesia"”.

\footnotetext{
${ }^{6}$ El teólogo Jon Sobrino había sido el único superviviente del asesinato de los jesuitas de la UCA por no encontrarse en el país en aquella fatídica fecha de 1989.

${ }^{7}$ La nota explicativa a la notificación del Vaticano sobre las obras del Jon Sobrino puede encontrarse en: $<$ http://www.vatican.va/roman_curia/congregations/cfaith/documents/rc_con_cfaith_doc_20061126_notasobrino_sp.html>, consultado è 12 de Enero de 2013. Para un estudio en profundidad de esta notificación
} 
Lo cables puestos al descubierto en el Vatileaks revelan que todavía en el 2007 la cuestión de la Teología de la Liberación seguía preocupando a los EE UU. Por ejemplo, un cable titulado "Socios por el Progreso", con fecha de Enero de 2003, la embajada de EE UU en el Vaticano dejaba claro que los EE UU y el Vaticano estaban en plena sintonía cuando se trata de su oposición a la Teología de la Liberación. La embajada declara:

La propia Santa Sede parece haber hecho un cambio filosófico en los últimos años respecto a su enfoque hacia el desarrollo y reflejan una posición más cercana a la del USG (Gobierno de EE UU).

Otro cable, con fecha 6 de mayo de 2007, bajo el encabezamiento de "La amenaza de la Teología de la Liberación" reza así:

Otro importante problema contextual de la visita (del Papa Benedicto XVI a Brasil) es el desafío a la Iglesia tradicional representado por la Teología de la Liberación. El Papa Juan Pablo (con la ayuda del actual Papa cuando era Cardenal Ratzinger) hizo grandes esfuerzos para acabar con este análisis marxista de la lucha de clases. Había llegado a ser promovido por una cantidad significativa de clérigos y gente común católica, quienes en un compromiso político apoyaban a veces la violencia por cuenta del pueblo. La forma más ortodoxa de la Teología de la Liberación que se ponía de parte de los pobres y oprimidos había experimentado una lectura reduccionista que el Vaticano quería corregir. En gran medida, el Papa Juan Pablo II desanimó la Teología de la Liberación, pero en estos últimos años ésta ha presenciado un resurgimiento en diversas partes de Latinoamérica.

Este resurgimiento y resiliencia del tema de la Teología de la Liberación también queda expresado en otro cable con fecha de Enero de 2008 con el motivo de la visita del Papa Benedicto a Cuba.

\section{La Guerra Fría cultural como elemento catalizador}

Durante la Guerra Fría, las actuaciones y las operaciones encubiertas de la CIA no se limitaron al ámbito político o militar, sino que se ampliaron al ámbito intelectual o de las ideas. El objetivo era apartar sutilmente a la intelectualidad europea de su fascinación por el marxismo y el comunismo, a favor de un imaginario social y político más acorde con el concepto americano. Frances Stonor Saunders (2001)

recomiendo al lector interesado el Cuaderno de Cristianismo y Justicia núm. 148, disponible en la URL: $<$ http://www.cristianismeijusticia.net/files/es148.pdf $>$, consultado el 14 de Noviembre de 2013. 
documenta cómo algunos de los más elocuentes exponentes de la libertad intelectual en el mundo occidental se convirtieron, consciente o inconscientemente, en instrumentos de los servicios secretos estadounidenses.

Entre las maniobras de la CIA se encontraban buscar el descrédito de intelectuales significados de la izquierda, la captación de "desengañados" y la confección de campañas de contra-información cultural que incluían la organización de congresos, exposiciones, conciertos y un sinfín de actividades además de subvencionar ambiciosos programas editoriales y costosas traducciones de ciertas obras. Muchas de las revistas europeas compensaban sus balances gracias a generosos mecenas tras los cuales se escondía la sombra alargada de la CIA.

El acto central de esta campaña de manipulación y propaganda, fue el Congreso para la Libertad de la Cultura, organización tapadera creada por el agente de la CIA Michael Josselson en 1950 y que duraría hasta 1967 (Warner, 1995). En su momento álgido, el Congreso para la Libertad de la Cultura contaba con oficinas en 35 países, decenas de personas contratadas y publicaciones periódicas en más de una veintena de revistas de prestigio.

Estas operaciones eran encubiertas o, quizás, no tanto, porque como escribe la autora:

La gran escala a la que se lanzó el Congreso en una época en que Europa estaba en la ruina parecía confirmar el rumor de que no se trataba del acontecimiento espontáneo e independiente que proclamaban sus organizadores. Años después, Tom Branden, de la CIA, razonaba que era suficiente tener algo de sentido común para saber quién estaba tras el Congreso: "Tenemos que recordar que estábamos hablando de una época en que Europa estaba arruinada. Si alguien tenía un céntimo, probablemente se trataba de alguna organización criminal. No había nada de dinero. Porque, claro está, la pista del dinero conducía a Estados Unidos (Saunders, 2001: 104).

En la sesión de clausura de un Congreso organizado en Milán en 1955, en el que se habló por primera vez del "fin de las ideologías", se dio lectura a un manifiesto programático y político titulado "Manifiesto por la libertad" en el que se expresó lo siguiente:

La libertad intelectual es uno de los derechos inalienables del hombre [...] Esta libertad se define fundamentalmente por su derecho a mantener y expresar las propias opiniones $y$, en particular, opiniones que difieran de las de sus gobernantes. Privado del derecho a decir "no" el hombre se convierte en esclavo [...] Ninguna raza, nación, clase o religión puede reclamar para sí el exclusivo derecho a representar la idea de libertad, ni el derecho a negar la libertad de otros grupos o credos en nombre de ningún ideal u objetivo supremo. Pensamos que la contribución histórica de toda sociedad hay que juzgarla por la amplitud y la cualidad de la libertad de la que gozan en realidad sus miembros [...] Los medios de coerción en los Estados totalitarios 
(soviéticos, se entiende) sobrepasan con mucho los de todas las anteriores tiranías de la historia de la humanidad (Saunders, 2001: 105).

Cabe resaltar para nuestro propósito la frase "ninguna raza, nación, clase o religión pude reclamar para sí el exclusivo derecho a representar la idea de libertad". Esta posición no deja de estar en contraposición con el imaginario mismo norteamericano y de su mito fundacional y proceso constituyente reflejado de manera magistral en la Carta de América elaborada por varios intelectuales americanos para justificar la guerra contra el terrorismo después de los atentados del 11S. Puede consultarse a este respecto las reflexiones de Fernando Quesada (2008: 143-164) sobre el concepto de democracia americana como religión civil. De la misma manera, dentro de este imaginario, los presidentes de una nación que se autopercibe como pueblo elegido desarrollan una especie de vocación redentora. Según el tipo de personalidad y desempeño del cargo cabe distinguir entre presidentes predicadores (Monroe, Eisenhower, Reagan, W. Bush) y presidentes pastores (Lincoln, Kennedy, Carter, Clinton). Los predicadores son aquellos más impetuosos y vehementes, movilizadores para la acción por confiar en una misión de la que se creen custodios. Los pastores, por su parte, resultan mucho más conciliadores en su discurso, por lo que éste es más abierto a la interpretación personal de la ciudadanía (Sánchez- Bayón, 2012: 198).

Entre los intelectuales que trabajaron para el Congreso había nombres que después se convirtieron en clásicos de la filosofía política o la teoría política y que hoy en día son objeto de estudio en las universidades. Algunos ejemplos de una larga lista son Arthur Koestler, André Malraux, Salvador de Madariaga o el mismo Bertrand Russel, que pocos años después rompería con la organización tras bascular él mismo hacia los postulados de la izquierda.

El conocimiento sobre esta Guerra Fría cultural encubierta aporta aún más luz sobre la interpretación que el gobierno americano hizo de la Teología de la Liberación como un elemento peligroso y subversivo cultural, ideológica y políticamente. Por lo demás, parece conveniente apuntar que en el caso particular de América Latina, como señala la reciente obra de Benedetta Calandra y Marina Franco (2013), esa guerra cultural se manifestó también como una especia de soft power o "poder blando" que actuó en paralelo a la mano dura de la CIA, tratando de exportar el American Way of Life y que abarcó actores de cine, medios de prensa, fundaciones culturales, organizaciones filantrópicas como la Ford Foundation y predicadores religiosos ${ }^{8}$.

Las asociaciones filantrópicas han sido objeto de estudio para Volker R. Berghahn que profundiza en las distintas actividades realizadas por éstas con el fin

\footnotetext{
${ }^{8}$ Un ejemplo, aunque no el único, lo constituirían los dibujos animados de Walt Disney.
} 
de promover el poder político, económico o cultural de EE.UU y su estrecha colaboración con Washington, considerando a la Fundación Ford como el mejor exponente de sus planteamientos. A su vez, cabe señalar la aparición de algunas biografías centradas en figuras tan importantes como Nelson A. Rockefeller o Shepard Stone, que han aportado un mayor conocimiento sobre las iniciativas promovidas desde algunas de estas fundaciones (Berghahn, 2001: 143-213).

\section{El nuevo Papa y la Teología de la Liberación}

Durante siglos Latinoamérica fue considerada por la Iglesia Católica como tierra de misión. Ni siquiera tenía voz y voto en el Vaticano y su Curia. Pero en los últimos treinta años, tres papas sucesivos (Pablo VI, Juan Pablo II y Benedicto XVI) visitaron todos los países latinoamericanos. El mismo Francisco, apenas elegido, anunció su presencia en Río (Brasil) el 23 de Julio de 2013.

Los cardenales reunidos en el cónclave el 13 de Marzo de 2013 eligieron un programa y un perfil adecuado para llevarlo a cabo. Bergoglio había permanecido alejado de los diferentes grupos de interés del Vaticano, lo cual lo hacía un candidato de interés, percibido como neutral, para comenzar la enorme tarea de una purificación interna de la institución que pudiera captarse clara y nítidamente de puertas para fuera después de los continuos escándalos de una y otra índole que habían asediado a la institución y de la insólita dimisión de Benedicto XVI.

La noticia causó sorpresa a propios y extraños, pues nunca antes se había elegido un Papa que no fuese europeo. Quizás lo que sucedió aquel día de marzo de 2013 deba entenderse también, como afirma Jean Jacques Kourliandsky (2013: 57), como un gesto de la diplomacia vaticana con respecto a Latinoamérica.

El recién ascendido a la cátedra de Pedro, antiguo cardenal Bogloglio y hoy Papa Francisco, en una de sus primeras intervenciones públicas ha dejado claro que le gustaría "una Iglesia pobre y para los pobres". Éste no deja de ser un discurso programático para su pontificado. El propio nombre escogido para su pontificado, Francisco, nos hace recordar a un santo muy vinculado a la pobreza como fue San Francisco de Asís.

La primera parte de la afirmación hace referencia a cuestiones intra-eclessia, es decir, dentro de la Iglesia. Más concretamente la reforma, tan necesaria y ansiada, de la Curia Vaticana y el control de los aspectos financieros del Instituto de las Obras de Religión (IOR), poniendo así fin a una arquitectura financiera caótica.

No podemos olvidar que ya el difunto Juan Pablo II trató de lidiar con el caso Marcinkus, pero recientemente ha sido el Consejo de Europa quien le ha sugerido al Vaticano reforzar la supervisión contra el blanqueo de capitales después de que fuera el mismo Vaticano quien le pidiera esa evaluación. En respuesta a esta petición, y quizás como una muestra de buena disposición a colaborar, el Vaticano ha contratado los servicios de Rene Bruelhart, abogado suizo y director de la unidad de 
inteligencia financiera de Lichtenstein. Pero esta disposición a colaborar no oculta ni un ápice la realidad que insinúa el consejo de Europa y que quizás haya querido desempolvar sabiamente el mismo Benedicto XVI.

La segunda parte es la que despierta más dudas en cuanto a su plasmación práctica. El Papa puede tener en mente una Iglesia volcada hacia los pobres desde la espiritualidad y la austeridad en los gestos y en las obras y, por tanto, enfocada a la caridad, o una Iglesia comprometida en lo social y que apoya la justicia social como un elemento esencial a la hora de combatir dicha pobreza estructural. En esta última posibilidad las posibles conexiones con la Teología de la Liberación parecen más que evidentes. Algunos sectores eclesiales ya lo han entendido de este modo pero, en mi opinión, se han precipitado en sus conclusiones.

Hay que tener presente que el nuevo Papa no es ni mucho menos el perfil progresista que anuncian a bombo y platillo algunos medios de comunicación y en éste sentido caben pocos cambios en cuanto a disciplina moral y doctrinal ${ }^{9}$. Sin embargo, la necesidad de una cara nueva para la Iglesia parece más que evidente, como también lo es que los cardenales han elegido un perfil y un programa para llevarla a cabo. Un rasgo de ese nuevo rostro lo constituiría, sin lugar a dudas, el basculamiento hacia posiciones más flexibles con el compromiso social, pero parece no ser, ni mucho menos, el más importante. Más bien se trata de un giro copernicano intencionado hacia la espiritualidad más tradicional aportada por las órdenes religiosas, entre las que figura la Compañía de Jesús, en detrimento de los movimientos neoconservadores de nueva cuña. Por ello no parece descabellado el pensar que se busca que estos nuevos movimientos, más centrados en cuestiones morales y doctrinales, mantengan un perfil bajo para ir poco a poco pasando a un segundo lugar y dejar la primacía a las tradicionales órdenes religiosas, más focalizadas en lo espiritual y lo intelectual. De ser esa la intención, la iniciativa encontraría no pocas resistencias y escollos que superar dentro de la misma estructura jerárquica más conservadora.

Aunque algunos teólogos de la liberación como Leonardo Boff se muestren ilusionados, no hay que olvidar que en el periodo 1971-1976 el nuevo Papa llegó a ser

\footnotetext{
${ }^{9}$ De hecho, tras las esperanzas iniciales puestas en el Papa Francisco en aras de una renovación eclesial profunda, las últimas decisiones del Vaticano de dar de nuevo carta de legitimidad a los Legionarios de Cristo - cuyo fundador, Marcial Maciel, mantuvo una doble vida entre la pederastia, los hijos secretos y numerosos escándalos económicos- y de canonizar al difunto Juan Pablo II - cuyo trato personal al padre Arrupe no fue del todo evangélico, junto con su decisión de intervenir la Compañía de Jesús, y al que se acusa de haber conocido los casos de pederastia de Maciel y no haber actuado en consecuencia- han decepcionado a un sector importante de los fieles católicos. Todo parece indicar que la canonización conjunta de Juan Pablo II y la de Juan XXIII es un esfuerzo desde el Vaticano para intentar reconciliar las tensiones entre los sectores conservador y progresista de la Iglesia. Tales son las dudas generadas que incluso un número reciente de la revista Política Exterior se hace eco de esto en un artículo con el sugerente título de: “Un año de Francisco I: ¿Superhéroe o cuerpo incierto?” (2014).
} 
provincial de la Compañía de Jesús en Argentina y, desde su puesto, se opuso firmemente a la Teología de la Liberación llamando al orden a algunos de sus hermanos jesuitas y no actuó, al menos públicamente, contra los generales golpistas que dirigían con mano de hierro el país. Pero sí lo hizo contra presidentes democráticamente electos como Néstor y Cristina Kirchner cuando presentaron al Parlamento leyes para permitir el aborto y el matrimonio homosexual.

La Teología de la Liberación con este Papa seguramente tendrá más historia y más pasado que presente y futuro pero, eso sí, una historia formalmente reconocida y valorada con gestos cargados de simbolismo como la canonización - tan deseada por un pueblo que ya lo aclama como santo- de monseñor Oscar Romero.

\section{Bibliografía}

Berghahn, Volker R. (2001) America and the Intellectual Cold Wars in Europe. Princeton: Princeton U. P.

Calandra, Benedetta, y Franco, Marina (2013) La guerra fría cultural en Latinoamérica. Desafíos y límites para una nueva mirada de las relaciones interamericanas. Buenos Aires: Editorial Biblos.

Ezcurra, Ana María (1986) El Vaticano y la administración Reagan. Madrid: Editorial IEPALA.

Gillis, Chester (2013) "La influencia vaticana en las políticas públicas de Estados Unidos". Vanguardia Dossier, núm. 48, pp.51-53.

Rajewski, Andrzej (2008) "Security Services of the Polish People's Republic Against the Vatican in 1956-1978", en A. Grúnová (comp.) NKDV/KGB Activities and Its Cooperation with Other Secret Services in Central and Eastern Europe 1945-1989. Bratislava: Nation's Memory Institute. [Disponible en la URL: $<$ http://nsarchive.files.wordpress.com/2013/05/bul-nkvd-aj.pdf $>$, consultada el 12 de Enero de 2014].

Kourliandsky, Jean Jacques (2013) “América Latina: una persistente prioridad de la Santa Sede". Vanguardia Dossier, núm. 48, 57-61.

Leffler, Melvyn P. (2008) La Guerra después de la guerra: Estados Unidos, la Unión Soviética y la Guerra Fría. Barcelona: Editorial Crítica.

Lowenthal, Abraham (1983) "Ronald Reagan y Latinoamérica: Enfrentamiento con la hegemonía declinante". Revista Foro Internacional (Centro de Estudios Internacionales), vol. 24, núm. 1, 21-49.

Quesada, Fernando (2008) Sendas de la democracia. Entre la violencia y la globalización. Madrid: Editorial Trotta.

Rabadán, Eliseo (2012) Filosofía y Teología de la liberación latinoamericana. Santiago de Chile: Centro de Estudios Miguel Enríquez. [Disponible en la URL: $<$ http://www.archivochile.com/carril_c/cc2012/cc2012-053.pdf >, consultado el 12 de Febrero de 2014]. 
Ros, Enrique (2002). Ernesto Che Guevara: Mito y realidad. Miami: Ediciones Universal.

Sánchez-Bayón, Antonio (2012) Estado y religión de acuerdo con los Estados Unidos de América: Análisis y sistematización del modelo relacional. Saarbrücken (Alemania): AV Akademikerverlag GmbH \& Co. KG, EAE.

Saunders, Frances Stonor (2001) La CIA y la guerra fría cultural. Madrid: Editorial Debate.

Selser, Gregorio (1988) El Documento de Santa Fe, Reagan y los derechos humanos. México D. F.: Editorial Alpa Corral.

Somiedo, Juan Pablo (2013) La geopolítica vaticana: de Juan Pablo II a Benedicto $X V I$. Madrid: Instituto Español de Estudios Estratégicos. [Disponible en la URL: $<$ http://www.ieee.es/Galerias/fichero/docs_opinion/2013/DIEEEO16-

2013_Geopolitica_Vaticano_JPSomiedo.pdf $>$, consultada el 21 de Enero de 2014].

Warner, Michael (1995) "Origins of the Congress of Cultural Freedom, 1949-1959". Studies in Intelligence, núm. 38. [Disponible en la URL: $<$ https://www.cia.gov/library/center-for-the-study-of-intelligence/csipublications/csi-studies/studies/95unclass/Warner.html>, consultada el 1 de Diciembre de 2013].

\section{Documentos oficiales del Vaticano}

Instrucción Libertatis Nuntius (Instrucciones sobre algunos aspectos de la Teología de la Liberación) (1984) [Disponible en la URL: $<$ http://www.vatican.va/roman_curia/congregations/cfaith/documents/rc_con_cf aith_doc_19840806_theology-liberation_sp.html>, consultado el 12 de Junio de $201 \overline{3}$ ].

Instrucción Libertatis Conscientia (Instrucción sobre libertad cristiana y liberación) (1986) [Disponible en la URL: $<\mathrm{http}$ //www.vatican.va/roman_curia/congregations/cfaith/documents/rc_con_cf aith_doc_19860322_freedom-liberation_sp.html>, consultado el 12 de Junio de 2013].

\section{Cables Wikileaks}

Cable Enero 2003. Disponible en la URL: $<$ http://wikileaks.org/cable/2003/01/03VATICAN283.html>, consultado el 14 de Enero de 2014.

Cable Mayo 2007. Disponible en la URL: $<$ http://wikileaks.org/cable/2007/05/07VATICAN85.html>, consultado el 14 de Enero de 2014. 
Cable Enero 2008. Disponible en la URL: $<$ http://wikileaks.org/cable/2008/01/08VATICAN14.htmll, consultado el 14 de Enero de 2014.

\section{Elementos multimedia}

La Guerra Fría en América Latina. Disponible en la URL: $<$ http://www.youtube.com/watch? $v=$ TbgwzPJOBt8>, consultada el 3 de Enero de 2014.

Entrevista a Jon Sobrino sobre los asesinatos de los jesuitas de la UCA en el Salvador. Disponible en la URL: $<\mathrm{http} / /$ www.youtube.com/watch? $\mathrm{v}=\mathrm{ZDcDmUqCpLc}>$, consultada el 12 de Noviembre de 2013.

Documental sobre las circunstancias y el operativo militar que rodearon el asesinato de los jesuitas españoles en el Salvador. Disponible en la URL: $<$ http://www.youtube.com/watch? $\mathrm{v}=\mathrm{TWm} 4 \mathrm{sKN} 4-\mathrm{xs}>$, consultada el 29 de Noviembre de 2013.

Entrevista al autor. Disponible en la URL: $<$ http://www.youtube.com/watch?v=KOzuBMwvHsY>, consultada el 14 de Febrero de 2014.

Ponencia en la Universidad de El Salvador sobre el esclarecimiento del asesinato de Monseñor Oscar Romero. Disponible en la URL:

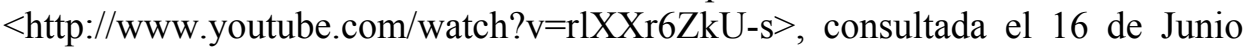
de 2013.

Teología de la Liberación, Disponible en la URL: $<\mathrm{http}$ ://www.youtube.com/watch? $\mathrm{v}=$ anGGLDjb0bM $>$, consultado el 27 de Abril de 2013. 